Article

\title{
Microbial Conversion of Vegetable Oil to Hydroxy Fatty Acid and Its Application to Bio-Based Polyurethane Synthesis
}

\author{
Tuan Kiet Tran ${ }^{1}$, Prasun Kumar ${ }^{1}{ }^{\mathbb{D}}$, Hak-Ryul Kim ${ }^{2}$, Ching T. Hou ${ }^{3}$ and Beom Soo Kim ${ }^{1, *}$ \\ 1 Department of Chemical Engineering, Chungbuk National University, Cheongju 28644, Korea; \\ ttkiet1987@gmail.com (T.K.T.); prasun@cbnu.ac.kr (P.K.) \\ 2 School of Food Science and Biotechnology, Kyungpook National University, Daegu 41566, Korea; \\ hakrkim@knu.ac.kr \\ 3 Renewable Product Technology Research Unit, National Center for Agricultural Utilization Research, ARS, \\ USDA, Peoria, IL 61604, USA; ching.hou@ars.usda.gov \\ * Correspondence: bskim@chungbuk.ac.kr; Tel.: +82-43-261-2372; Fax: +82-43-269-2370
}

Received: 26 July 2018; Accepted: 17 August 2018; Published: 19 August 2018

check for updates

\begin{abstract}
New polyurethanes were synthesized based on dihydroxy fatty acid obtained by the microbial conversion of olive oil. Monounsaturated 7,10-dihydroxy-8(E)-octadecenoic acid (DOD) was produced from olive oil by Pseudomonas aeruginosa PR3 and reacted with hexamethylene diisocyanate (HMDI) at different ratios to form polyurethanes. Fourier transform infrared spectroscopy and gas chromatography/mass spectrometry confirmed the synthesis of DOD. The thermal and tensile properties of the polyurethanes were investigated by differential scanning calorimetry, thermogravimetric analysis, and a universal testing machine. At an isocyanate/hydroxyl ratio of 1.4, the polyurethane exhibited an elongation at break of $59.2 \%$ and a high tensile strength of $37.9 \mathrm{MPa}$. DOD was also mixed with polycaprolactone diol or polyethylene glycol at different weight ratios and then reacted with HMDI to produce new polyurethanes of various properties. These polyurethanes displayed higher elongation at break and good thermal stability. This is the first report on the synthesis of polyurethanes based on DOD produced by the microbial conversion of vegetable oil.
\end{abstract}

Keywords: 7,10-dihydroxy-8(E)-octadecenoic acid; olive oil; polyol; polyurethane; Pseudomonas aeruginosa PR3

\section{Introduction}

Polyurethanes (PUs) are flexible polymeric materials containing a urethane group in their structure [1]. Due to their unique mechanical, physical, biological, and chemical properties, PUs are one of the most important polymers in many potential applications. They attracted researchers' attention owing to their cost-effective synthesis and use in a variety of commercial applications. PUs have been widely used in a variety of fields such as medicine, construction engineering, coatings, sealants, adhesives, foams, and composites because they can be shaped into the form of fibers, films, castables, thermoplastics, and foams [2-6]. PUs are typically synthesized by reacting a polyol containing two or more hydroxyl groups $(\mathrm{OH})$ with an isocyanate containing two or more isocyanate groups $(\mathrm{NCO})$. There are a limited number of isocyanates that can be used in the chemical industry due to their toxicity. In contrast, many polyols are available, but most of the materials used to synthesize polyols are petroleum-based and thus cause environmental problems [7]. Therefore, the production of isocyanates and polyols using renewable resources has received considerable interest from many scientists around the world [8-13]. 
In recent years, renewable resources for raw materials have not only contributed to sustainable development but also helped to address environmental problems, waste disposal, and non-renewable resource depletion. In this context, vegetable oils are the most ideal renewable resources and have increasingly been utilized in the spotlight of the chemical and polymer industries. These oils possess certain reliable characteristics including universal convenience, inherent biodegradability, low cost, and low eco-toxicity [14]. The main sources of oil, namely palm trees, soybeans, rapeseed, cotton, sunflower, palm kernel, olive, and coconut, are being explored for beneficial improvements in research and development. As a result, bio-oil derived polymers or composites are widely applied to paints, coatings, adhesives, and biomedicine. In particular, vegetable oils are triglycerides containing long chain fatty acids such as oleic acid, linoleic acid, and linolenic acid that can be used to produce hydroxy fatty acids (HFAs). HFAs are known to have higher viscosity and reactivity than other fatty acids. Due to these features, HFAs have enormous potential in industrial applications including plastics, waxes, nylons, lubricants, cosmetics, and paint additives. Since HFAs were originally found in limited amounts in the plant system, recent studies have focused on microbial conversion processes of various unsaturated fatty acids to HFAs. Pseudomonas aeruginosa PR3 is a known strain with the ability to convert many unsaturated fatty acids to mono-, di-, and tri-hydroxy fatty acids [15-20]. Among fatty acid substrates, oleic acid was efficiently used by strain PR3 to produce 7,10-dihydroxy-8(E)-octadecenoic acid (DOD) [21,22]. Due to the high content of oleic acid, olive oil can be used as a preferred substrate for DOD production by the PR3 strain [23,24]. DOD is a novel compound with two hydroxyl groups that can react completely with isocyanates to form PUs.

This study presents the first proof-of-concept for PU synthesis using DOD produced by P. aeruginosa PR3, using olive oil as a substrate. Here, the preparation of PU was carried out through a reaction mediated by hexamethylene diisocyanate (HMDI) in different ratios. In addition, DOD was mixed with different weight ratios of polyethylene glycol (PEG) (molecular weights 200, 2000, and 20,000) or polycaprolactone diol (PCLDO) (molecular weight 2000) and reacted with HMDI to form new PUs. Fourier transform infrared spectroscopy (FTIR) and gas chromatography/mass spectrometry (GC/MS) were used to verify the structure of the DOD. The prepared PUs were characterized by FTIR, differential scanning calorimetry (DSC), and thermogravimetric analysis (TGA). The tensile properties of the PUs were also measured and compared using a universal testing machine (UTM).

\section{Materials and Methods}

\subsection{Materials}

Olive oil (containing 73\% oleic acid) was obtained from Samchun (Seoul, Korea). PCLDO (molecular weight 2000), PEG (molecular weights 200 and 2000), and dibutyltin dilaurate (DBTDL) were purchased from Sigma-Aldrich (St. Louis, MO, USA). PEG (molecular weight 20,000) was purchased from Fluka (Buchs, Switzerland). HMDI was purchased from Daejung (Siheung, Korea). All other reagents were of analytical grade.

\subsection{Media and Cultivation Conditions}

P. aeruginosa PR3 (NRRL strain B-18602) was used in this study. The standard growth medium consisted of $4 \mathrm{~g} / \mathrm{L}$ glucose, $1 \mathrm{~g} / \mathrm{L}$ yeast extract, $4 \mathrm{~g} / \mathrm{L} \mathrm{K}_{2} \mathrm{HPO}_{4}, 1 \mathrm{~g} / \mathrm{L}\left(\mathrm{NH}_{4}\right)_{2} \mathrm{HPO}_{4}, 0.1 \mathrm{~g} / \mathrm{L} \mathrm{MgSO}{ }_{4}$, $0.056 \mathrm{~g} / \mathrm{L} \mathrm{FeSO}_{4}$, and $0.01 \mathrm{~g} / \mathrm{L} \mathrm{MnSO}_{4}$. The medium was adjusted to $\mathrm{pH} 8.0$ by dilute phosphoric acid [19]. The strain was grown aerobically in a 500-mL flask containing $100 \mathrm{~mL}$ of the standard medium at $28^{\circ} \mathrm{C}$ with shaking at $200 \mathrm{rpm}$.

\subsection{Production of DOD from Olive Oil}

After $24 \mathrm{~h}$ of cultivation on glucose, $1.1 \mathrm{~mL}(1.0 \% v / v)$ olive oil was added to the medium for DOD production and the mixture was incubated for an additional $72 \mathrm{~h}$. After the cultivation period (total $96 \mathrm{~h}$ ), the medium was acidified to $\mathrm{pH} 2$ with $6 \mathrm{~N} \mathrm{HCl}$, then extracted twice with an equivolume 
mixture of ethyl acetate and diethyl ether [23]. Finally, the solvents were removed by a rotatory evaporator and the product was washed with n-hexane and recrystallized in ethyl acetate. DOD was filtered and dried using a solvent dryer. All experiments were conducted independently and repeated three times. Data are represented as the mean \pm standard deviation.

\subsection{Preparation of PUs Based on DOD}

One gram of DOD was mixed with $1 \% w / v$ DBTDL and $3 \mathrm{~mL}$ chloroform in a beaker for $5 \mathrm{~min}$ at room temperature. HMDI was added to the beaker and mixed further for $10 \mathrm{~min}$. The molar ratio of $\mathrm{NCO}$ to $\mathrm{OH}$ was set at 1.0, 1.2, 1.4, and 1.6 by varying DOD and HMDI contents. Then, the mixture was poured onto a glass plate and post-cured at $80^{\circ} \mathrm{C}$ in a vacuum oven for $2 \mathrm{~h}$ [12]. The solvent was evaporated and the polymer films obtained after post-curing was peeled off from the plate. Films sliced into specific dimensions were used for thermo-mechanical testing.

\subsection{Preparation of PUs Based on DOD and PEG or PCLDO}

One gram of polyol was mixed with $1 \% w / v$ DBTDL and $3 \mathrm{~mL}$ chloroform in a beaker for $5 \mathrm{~min}$ at room temperature. As a polyol, DOD and PEG (molecular weights 200, 2000, and 20,000) or PCLDO (molecular weight 2000) were mixed at various weight ratios. HMDI was added to the beaker at a final molar NCO/OH ratio of 1.4 and mixed further for $10 \mathrm{~min}$. The mixture was casted on a glass plate and heated to $80^{\circ} \mathrm{C}$ in a vacuum oven for $2 \mathrm{~h}$.

\subsection{Analytical Methods}

\subsubsection{GC/MS}

For GC analysis, the sample was esterified first by diazomethane for $10 \mathrm{~min}$ at room temperature and then derivatized with the mixture of trimethylsilyl imidazole (TMSI) and pyridine $(1: 4, v / v)$ for $45 \mathrm{~min}$. The derivatized samples were analyzed by GC (Agilent model 6890N, Agilent, Santa Clara, CA, USA) equipped with an HP-5 column $(30 \mathrm{~m} \times 320 \mu \mathrm{m} \times 0.25 \mu \mathrm{m})$. The injection volume was $1 \mu \mathrm{L}$. The column was initially kept at $70{ }^{\circ} \mathrm{C}$ and raised to $200{ }^{\circ} \mathrm{C}$ at $20^{\circ} \mathrm{C} / \mathrm{min}$. After holding for $1 \mathrm{~min}$ at $200{ }^{\circ} \mathrm{C}$, it was further increased to $240{ }^{\circ} \mathrm{C}$ at $0.7^{\circ} \mathrm{C} / \mathrm{min}$ followed by holding at $240{ }^{\circ} \mathrm{C}$ for $15 \mathrm{~min}$ [19]. The detector and injector temperatures were $280^{\circ} \mathrm{C}$ and $230^{\circ} \mathrm{C}$, respectively. The methyl ester of heptadecanoic acid was used as an internal standard for quantification. The product structure was confirmed using GC/MS analysis (Agilent 6890/5973i GC/MSD, Agilent, Santa Clara, CA, USA) with a temperature gradient as follows: $70{ }^{\circ} \mathrm{C}$ to $170{ }^{\circ} \mathrm{C}$ at $20^{\circ} \mathrm{C} / \mathrm{min}$, holding at $170{ }^{\circ} \mathrm{C}$ for $1 \mathrm{~min}, 170{ }^{\circ} \mathrm{C}$ to $250{ }^{\circ} \mathrm{C}$ at $5{ }^{\circ} \mathrm{C} / \mathrm{min}$, and holding at $250{ }^{\circ} \mathrm{C}$ for $15 \mathrm{~min}$. The helium flow rate was $0.67 \mathrm{~mL} / \mathrm{min}$. For MS setup, ionization energy was maintained at $70 \mathrm{eV}$. The injection volume of each sample was $1 \mu \mathrm{L}$. The peaks were identified by comparing their fragmentation patterns with those of reference compounds.

\subsubsection{FTIR}

FTIR analysis was performed on a Nicolet model Magna-IR 200 FTIR spectrometer (Thermo Fisher Scientific, Waltham, MA, USA). The thin films of DOD and all PU samples were made using potassium bromide $(\mathrm{KBr})$ pellets with a sample/ $\mathrm{KBr}$ ratio of 1:100. Absorbance spectra were collected at wave numbers in the range of $4000-400 \mathrm{~cm}^{-1}$ as described previously [25].

\subsubsection{DSC and TGA}

DSC thermograms were obtained by using DSC Q2000 (TA Instruments, New Castle, DE, USA). Each 10-mg sample was cured dynamically by three steps. First, the samples were heated from $30{ }^{\circ} \mathrm{C}$ to $200{ }^{\circ} \mathrm{C}$ at $20{ }^{\circ} \mathrm{C} / \mathrm{min}$ and maintained at $200{ }^{\circ} \mathrm{C}$ for $5 \mathrm{~min}$. They were cooled to $-40{ }^{\circ} \mathrm{C}$ at $-20{ }^{\circ} \mathrm{C} / \mathrm{min}$ and maintained at $-40{ }^{\circ} \mathrm{C}$ for $5 \mathrm{~min}$. Finally, they were heated again to $200{ }^{\circ} \mathrm{C}$ at $10^{\circ} \mathrm{C} / \mathrm{min}$. TGA experiments were conducted by Discovery TGA (TA Instruments, New Castle, DE, 
USA) to determine the thermal decomposition behavior of PUs. All samples were heated from room temperature to $800{ }^{\circ} \mathrm{C}$ at a heating rate of $10^{\circ} \mathrm{C} / \mathrm{min}$ under $\mathrm{N}_{2}$ gas flow $(60 \mathrm{~mL} / \mathrm{min})$.

\subsubsection{Tensile Properties}

To measure the tensile properties of the PUs, polymer samples were prepared in dimensions of $50 \mathrm{~mm} \times 10 \mathrm{~mm}$. The test was performed using UTM (LR-30 K, Lloyd Instruments, Hampshire, UK) with a load cell of $1 \mathrm{kN}$ and a crosshead speed of $5 \mathrm{~mm} / \mathrm{min}$ at room temperature according to ASTM D638 [26,27]. The experiments were replicated at least five times.

\section{Results and Discussion}

The natural presence of at least one unsaturated fatty acid in the triacylglyceride structure of vegetable oils makes them an advantageous alternative to petroleum-based polyols. Incidentally, $P$. aeruginosa PR3 can convert these unsaturated fatty acids to HFAs through the action of triolein-induced lipase [19]. The resulting bio-based polyols may function as well as synthetic polyols for the generation of PUs using an isocyanate catalyzed reaction. Therefore, the aim of the present study was a proof-of-concept, i.e., to evaluate the efficacy of DOD for new bio-based PU synthesis.

\subsection{Production of DOD from Olive Oil}

Olive oil was used in this work as a renewable and inexpensive model substrate for HFA production. P. aeruginosa PR3 grown on glucose for $24 \mathrm{~h}$ could effectively convert $1 \%$ olive oil to DOD after an additional $72 \mathrm{~h}$ of cultivation. The cultures were treated with organic solvents to extract the product and subsequently analyzed by FTIR and GC/MS. The FTIR spectrum indicated the presence of hydroxyl groups having a transmittance at $3337 \mathrm{~cm}^{-1}$ as well as the presence of a carboxyl group at $1696 \mathrm{~cm}^{-1}$. The transmittance at $961 \mathrm{~cm}^{-1}$ confirmed that the product was composed of trans-unsaturation (Figure 1). The peaks identified by FTIR corroborate with those obtained previously on DOD [26].

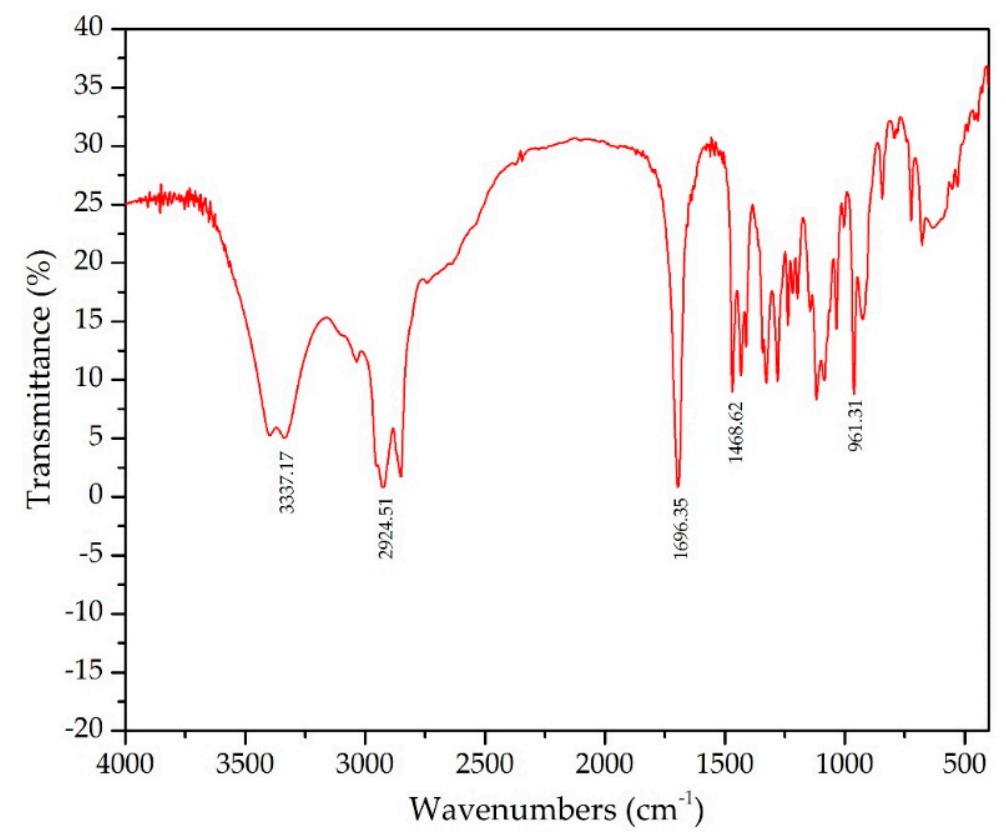

Figure 1. FTIR spectra of the product produced from olive oil by Pseudomonas aeruginosa PR3.

The extract was methylated by diazomethane and derivatized using a mixture of TMSI and pyridine prior to GC/MS analysis. The GC profile showed one main peak with a retention time of $15.503 \mathrm{~min}$, and the area percentage of this peak was $94 \%$ of the total peaks excluding the internal 
standard (data not shown). Figure 2 shows the electron impact MS analysis of methylated TMS derivatives. The peak at $m / z 215$ represents a fragment containing one TMS group, while the peak at $m / z 343$ represents a fragment containing two TMS groups and a double bond. Two other significant peaks at $m / z 231$ and $m / z 359$ represent two fragments involved in the methylated carboxyl group containing one TMS group and two TMS groups with a double bond, respectively. The presence of a peak at $m / z 472$ can be attributed to the molecular mass of the TMS derivative of the methylated product. The plausible mass fragmentation routes (colored arrows) are also graphically represented in Figure 2. These fragments assigned a double bond at C8-9 and two hydroxyl groups at C7 and C10. The fragmentation patterns obtained through GC/MS analysis support previous observations made for DOD identification [22,23]. The results obtained by FTIR and GC/MS confirm the bioconversion of olive oil to DOD by strain PR3.

In this study, olive oil was used as a model substrate and can be replaced by many other cheap vegetable oils containing high oleic acid content (e.g., sunflower oil, canola oil, and palm oil containing $82 \%, 61 \%$, and $36.6 \%$ oleic acid, respectively). Recently, DOD production was reported using Philippine nut oil and palm oil, demonstrating that cheap oil substrates may also be used for this purpose [28].

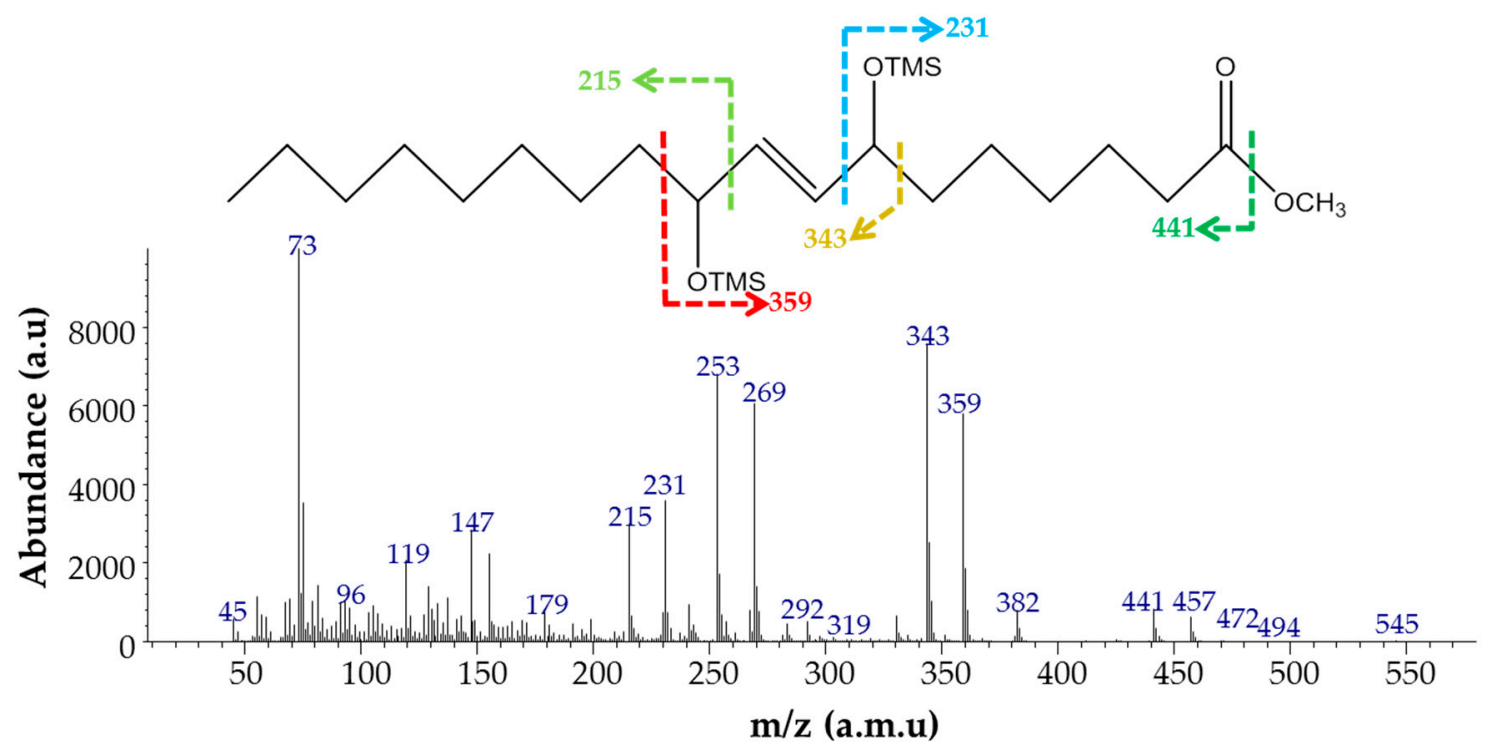

Figure 2. EI mass spectra of the major product produced from olive oil by Pseudomonas aeruginosa PR3.

\subsection{Synthesis of PUs from DOD (PU-DOD)}

Since the DOD produced through the bioconversion of olive oil contains two hydroxyl groups, the potential for PU formation using DOD was evaluated. To achieve this, PU-DOD was prepared by reacting DOD and HMDI with four different NCO/OH ratios (1.0, 1.2, 1.4, and 1.6). Preliminary experiments performed at low $\mathrm{NCO} / \mathrm{OH}$ ratios of less than 1.0 showed that DOD could not be effectively linked with HMDI and that the sample remained in a liquid state. On the other hand, when the ratio exceeded 1.6, the polymer became more rigid and stuck to the glass plate. The FTIR spectrum of PU-DOD prepared from DOD and HMDI is shown in Figure 3. 


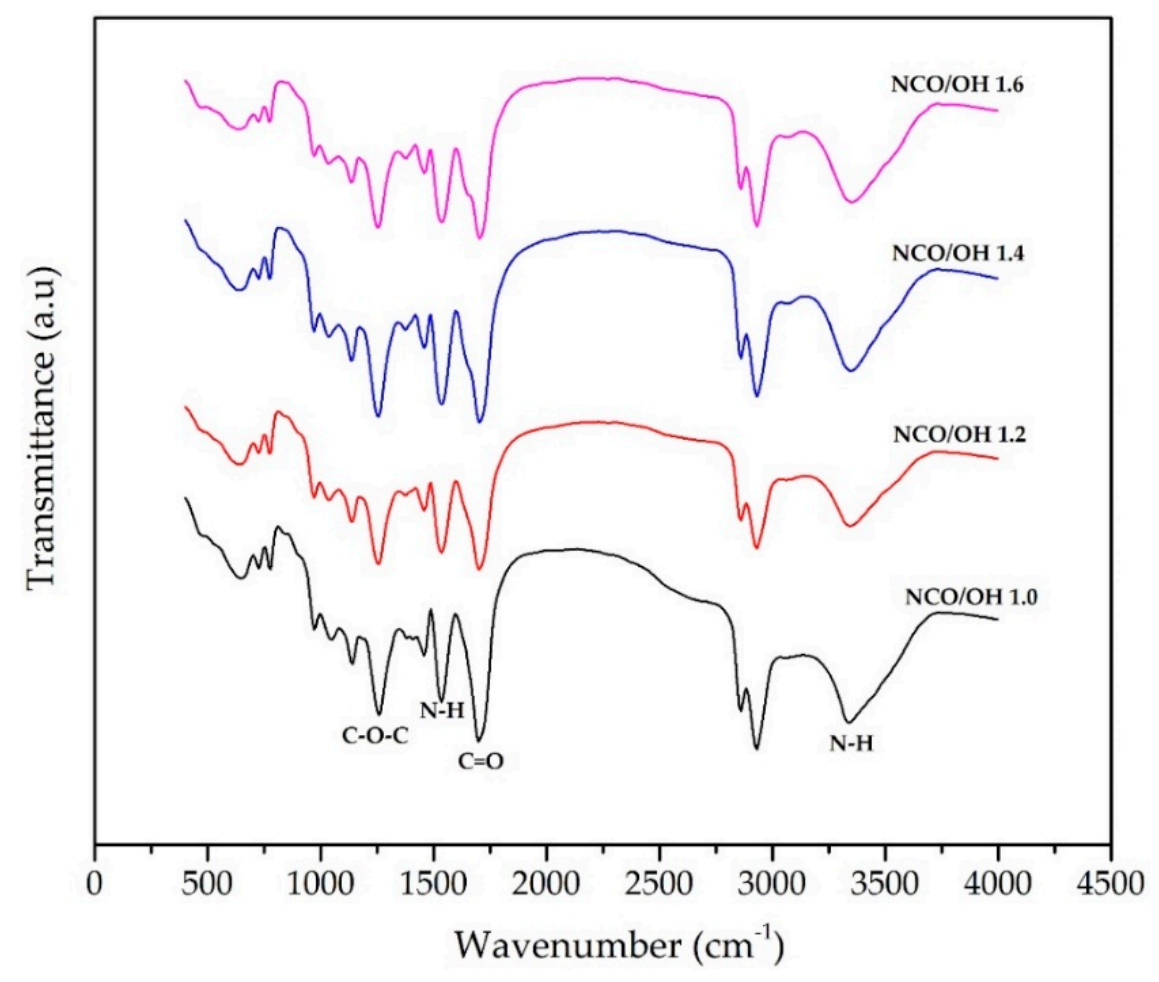

Figure 3. FTIR spectra of polyurethane-7,10-dihydroxy-8(E)-octadecenoic acid (PU-DOD) with different $\mathrm{NCO} / \mathrm{OH}$ ratios.

The bands located at $3410 \mathrm{~cm}^{-1}$ and $1537 \mathrm{~cm}^{-1}$ represent the $\mathrm{N}-\mathrm{H}$ group $(\mathrm{N}-\mathrm{H}$ stretching and $\mathrm{N}-\mathrm{H}$ bending, respectively). The amide carbonyl stretch at about $1699 \mathrm{~cm}^{-1}$ and the N-H bending vibration coupled to the $\mathrm{C}-\mathrm{N}$ stretch $\left(\right.$ at $1130 \mathrm{~cm}^{-1}$ ) arise possibly due to the reaction of the carboxyl group and $-\mathrm{N}=\mathrm{C}=\mathrm{O}$ [29]. The presence of a band at $1254 \mathrm{~cm}^{-1}$ of the $\mathrm{C}-\mathrm{O}-\mathrm{C}$ group confirms the formation of PU because both DOD and HMDI do not contain $\mathrm{C}-\mathrm{O}-\mathrm{C}$ bonds. The absence of a band at $2270 \mathrm{~cm}^{-1}$ of the $\mathrm{N}=\mathrm{C}=\mathrm{O}$ group confirms that all HMDI reacted with $\mathrm{OH}$ groups during polymerization $[30,31]$.

The glass transition temperature $\left(T_{g}\right)$ of PU-DOD was also measured. $T_{g}$ was taken as the mid-point or steepest slope of the inflection with the onset and outset temperatures defining the $T_{g}$ range $[10,12]$. The data is shown in Figure 4 and summarized in Table 1 . The $T_{g}$ of PU-DOD increased with increasing $\mathrm{NCO} / \mathrm{OH}$ ratio to 1.4 . The $T_{g}$ of the polymer was $11.3^{\circ} \mathrm{C}$ at a ratio of 1.0 and reached $13.6^{\circ} \mathrm{C}$ at a ratio of 1.4 (Table 1). As the ratio of $\mathrm{NCO} / \mathrm{OH}$ increased, the reaction between the $\mathrm{NCO}$ and $\mathrm{OH}$ groups increased. There was no peak corresponding to the melting temperature. 


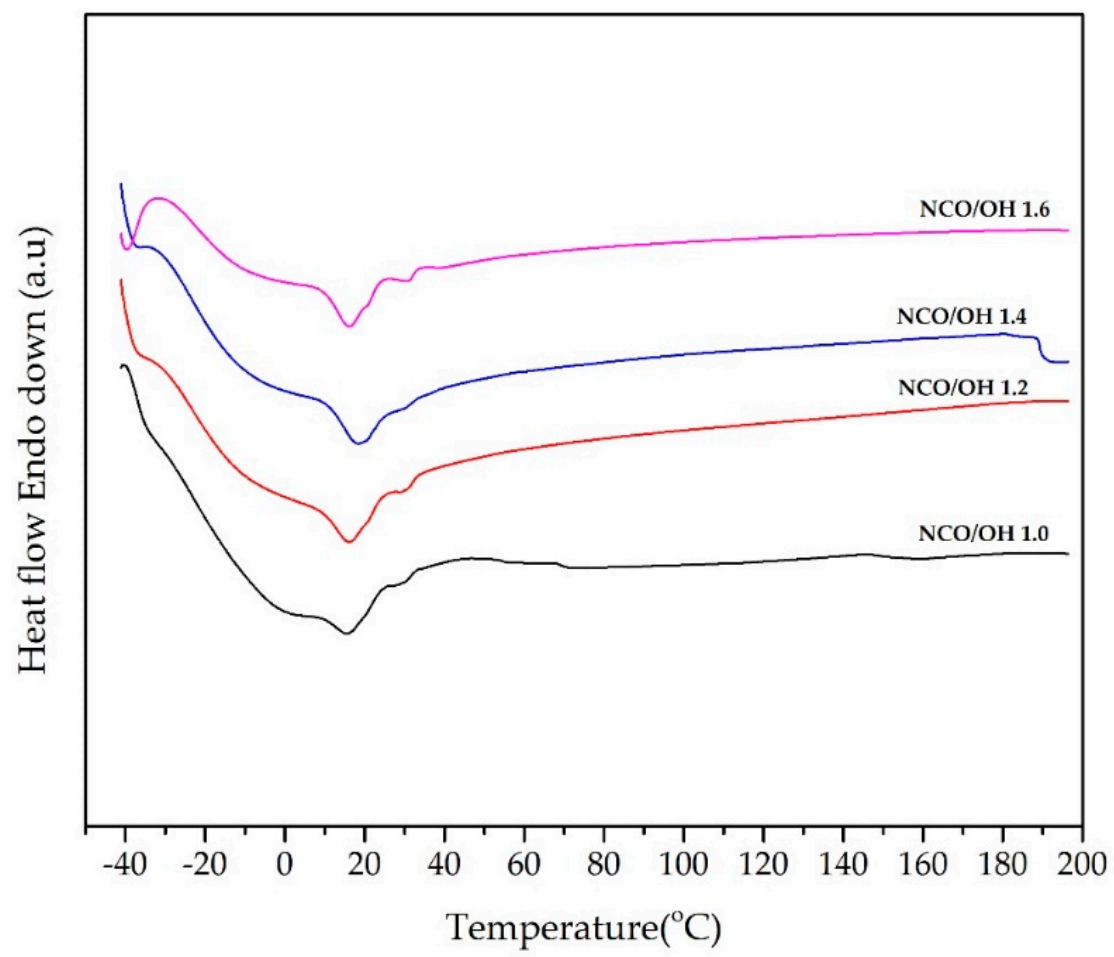

Figure 4. Differential scanning calorimetry (DSC) analysis of PU-DOD with different NCO/OH ratios.

Table 1. Thermal and mechanical properties of PU-DOD.

\begin{tabular}{ccccccc}
\hline \multirow{2}{*}{ NCO/OH Ratio } & $\boldsymbol{T}_{\boldsymbol{g}}\left({ }^{\circ} \mathbf{C}\right)$ & \multicolumn{3}{c}{ TGA in Nitrogen $\left({ }^{\circ} \mathbf{C}\right)$} & $\begin{array}{c}\text { Elongation } \\
\text { at Break (\%) }\end{array}$ & $\begin{array}{c}\text { Tensile Strength } \\
\text { (MPa) }\end{array}$ \\
\cline { 3 - 5 } & & $\boldsymbol{T}_{\mathbf{1 0} \%}$ & $\boldsymbol{T}_{\mathbf{5 0} \%}$ & $\boldsymbol{T}_{\max }$ (first/second) & & \\
\hline 1.0 & 11.3 & 248 & 398 & $298 / 458$ & $85.6 \pm 3.77$ & $10.1 \pm 1.58$ \\
1.2 & 12.0 & 260 & 407 & $298 / 452$ & $60.8 \pm 1.12$ & $10.3 \pm 0.14$ \\
1.4 & 13.6 & 262 & 414 & $304 / 463$ & $59.3 \pm 4.01$ & $37.9 \pm 4.40$ \\
1.6 & 12.3 & 272 & 400 & $315 / 461$ & $31.2 \pm 1.12$ & $16.9 \pm 1.36$ \\
\hline
\end{tabular}

The TGA and DTG weight loss curves of PU-DOD with different ratios of $\mathrm{NCO} / \mathrm{OH}$ are shown in Figure 5. For all PU-DOD samples, decomposition began at $200{ }^{\circ} \mathrm{C}$ and took place via three steps. The first step occurred in the range of $200-320^{\circ} \mathrm{C}$, which is related to the decomposition of unstable urethane bonds, e.g., the separation of $\mathrm{NCO}$ and $\mathrm{OH}$ groups, and the formation of primary and secondary amines. The second step was detected in the range of $320-470{ }^{\circ} \mathrm{C}$, which corresponds to the chain scission of polyols. The third step was started at a temperature higher than $470{ }^{\circ} \mathrm{C}$ (Figure 5). The existence of the third step at $470{ }^{\circ} \mathrm{C}$ can be explained by the decomposition of the fragments formed before the second step [32]. In addition, the $10 \%$ weight loss temperature $\left(T_{10 \%}\right)$ increased with increasing $\mathrm{NCO} / \mathrm{OH}$ ratio (Table 1) due to the possibility of trimer formation of the diisocyanate compound [30]. The temperatures of the maximum DTG peaks $\left(T_{\max }\right)$ for PU-DOD are slightly higher when the $\mathrm{NCO} / \mathrm{OH}$ ratio is high. 

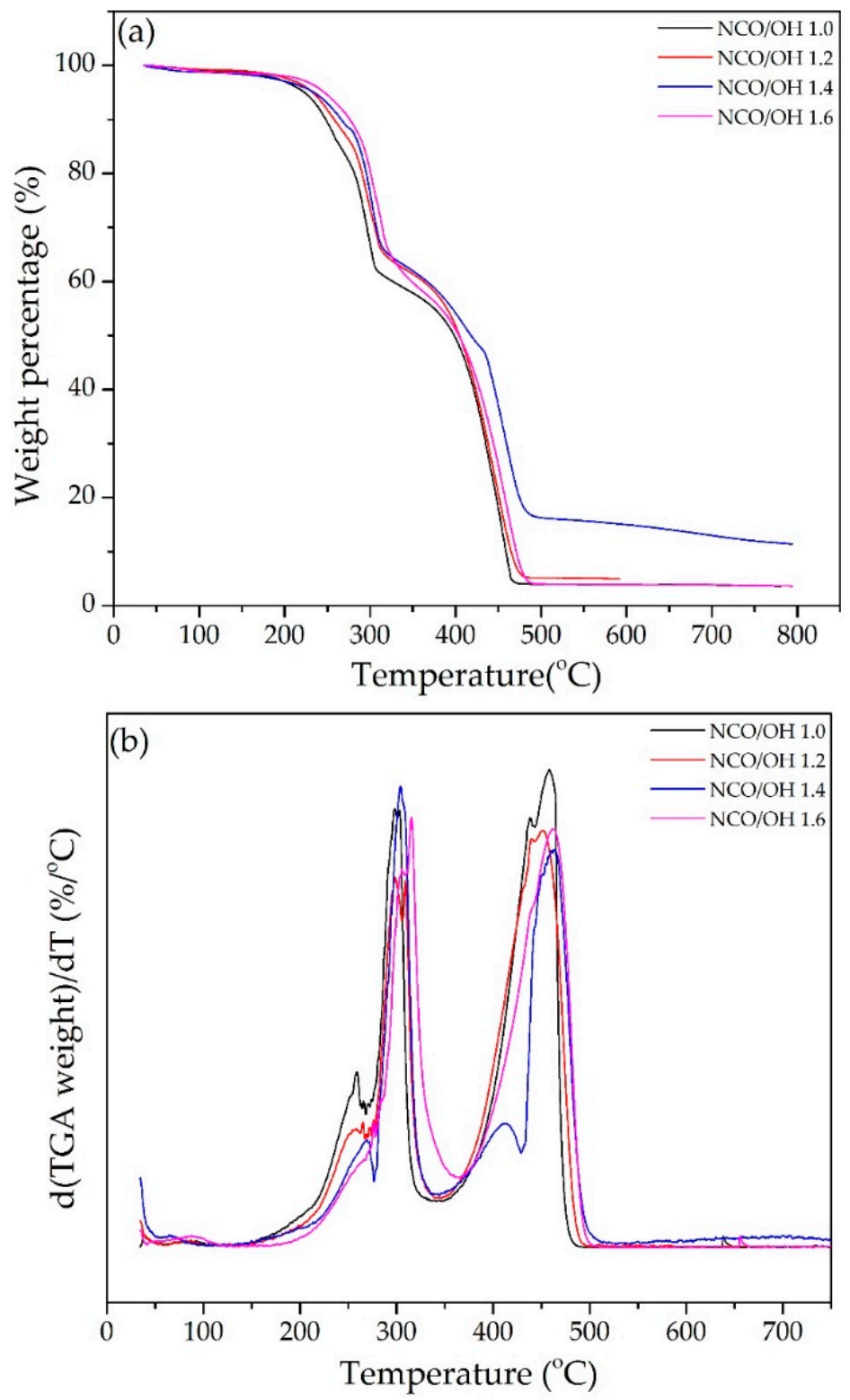

Figure 5. (a) Thermogravimetric analysis (TGA) curves and (b) their derivative curves of PU-DOD with different $\mathrm{NCO} / \mathrm{OH}$ ratios.

The tensile properties of the PU-DOD polymers obtained at different $\mathrm{NCO} / \mathrm{OH}$ ratios are summarized in Table 1. As mentioned earlier, PU-DOD became more rigid with increasing NCO/OH ratio, which explains why the elongation at break decreased with increasing the ratio. The elongation at break decreased from $85.6 \%$ at a ratio of 1.0 to $31.2 \%$ at a ratio of 1.6 . Apparently, the state of PU-DOD changed from ductile to brittle as the ratio increased. On the other hand, the tensile strength was the highest at $37.9 \mathrm{MPa}$ when the $\mathrm{NCO} / \mathrm{OH}$ ratio was 1.4 (Figure 6). Therefore, the optimum $\mathrm{NCO} / \mathrm{OH}$ ratio can be considered to be important for PU synthesis. A further increase in the ratio to 1.6 lowered the tensile strength due to the formation of the trimer. As the $\mathrm{NCO} / \mathrm{OH}$ ratio increased, the trimer content increased and the polymer became more brittle, which increased the tensile strength and decreased the elongation at break [30]. Such brittleness may also be attributed to the amide formation due to the reaction between the carboxyl group (of DOD) and NCO (of HMDI). Such a reaction may occur even at room temperature and involves mixed carbamic-carboxylic anhydride intermediates as described by others [29]. The carbon of $\mathrm{CO}_{2}$ generated during the reaction originates from isocyanate, although the exact mechanism is yet to be reported. 


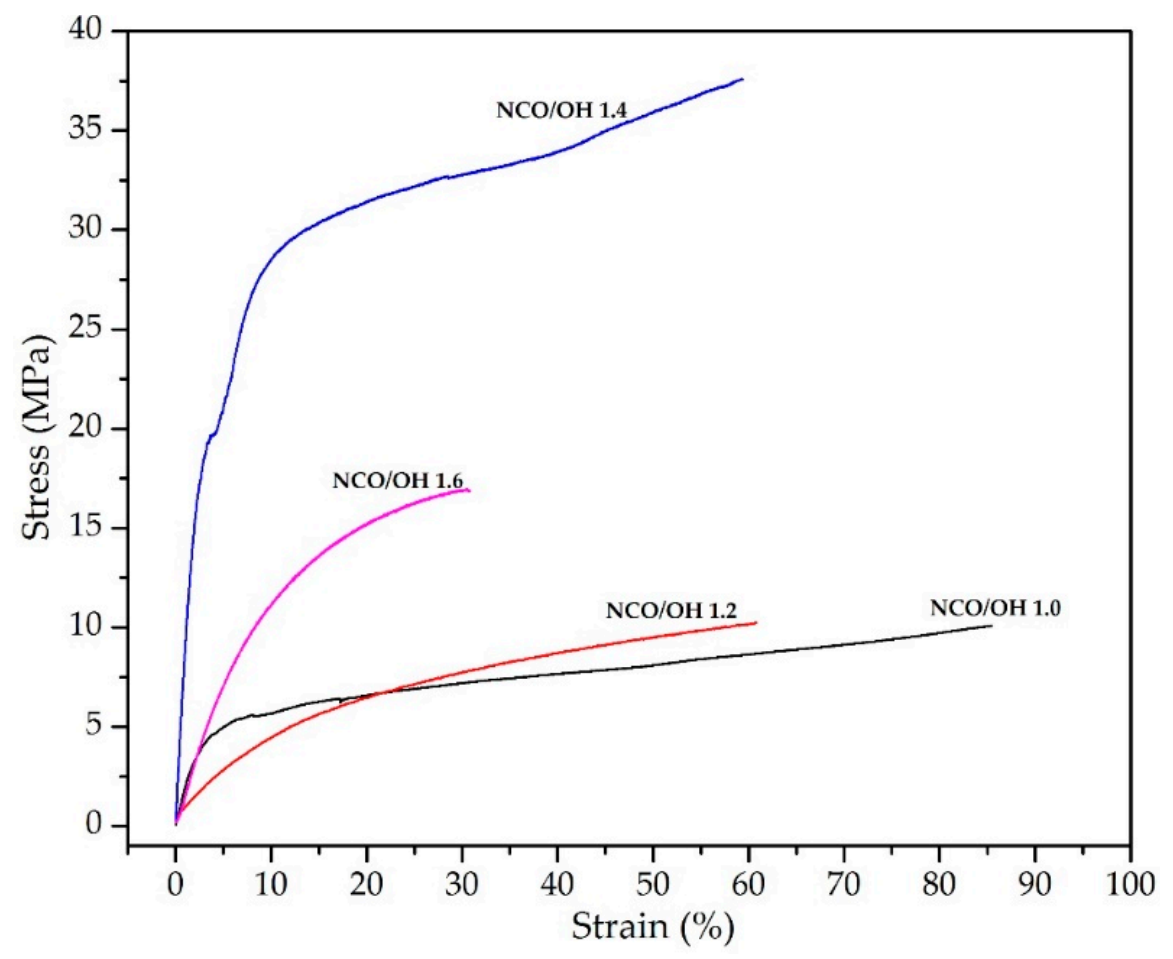

Figure 6. Stress-strain curves of PU-DOD with different $\mathrm{NCO} / \mathrm{OH}$ ratios.

\subsection{Synthesis of PUs from DOD and PEG or PCLDO (PU-DOD/PEG or PU-DOD/PCLDO)}

Attempts were made to enhance the diversity of the PU-DOD polymers. To achieve this, three kinds of PEG (molecular weights 200, 2000, 20,000) or PCLDO (molecular weight 2000) were mixed with DOD and reacted with HMDI to form new PUs termed as PU-DOD/PEG200, PU-DOD/PEG2K, PU-DOD/PEG20K, and PU-DOD/PCLDO, respectively. The chemical structures of DOD, PEG, and PCLDO as well as the reaction schemes to form PUs are shown in Figure 7.

The weight ratios of DOD to PEG or PCLDO were maintained at $2 / 1,1 / 1$, and $1 / 2$. The FTIR of all of these samples indicated the formation of PUs by peaks at $3400 \mathrm{~cm}^{-1}$ and $1550 \mathrm{~cm}^{-1}$ of the $\mathrm{N}-\mathrm{H}$ group, a peak around $1700 \mathrm{~cm}^{-1}$ of the $\mathrm{C}=\mathrm{O}$ group, and a peak at $1250 \mathrm{~cm}^{-1}$ of the $\mathrm{C}-\mathrm{O}-\mathrm{C}$ group (Figure 8). There was no stretching vibration band at $2270 \mathrm{~cm}^{-1}$ indicating the absence of the $\mathrm{N}=\mathrm{C}=\mathrm{O}$ group [31]. All of these observations resemble typical FTIR spectra of PU. 

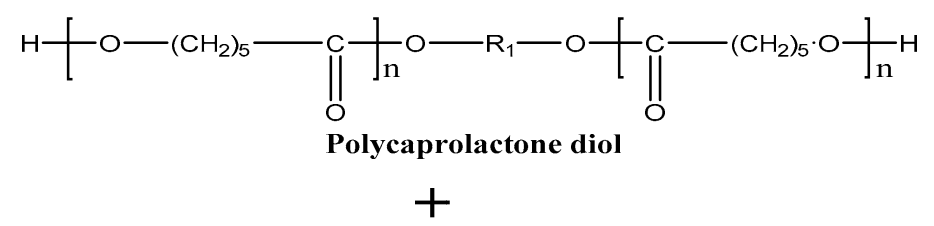<smiles>CCCCCCCCC(O)/C=C/C(O)CCCCCC(=O)O</smiles>

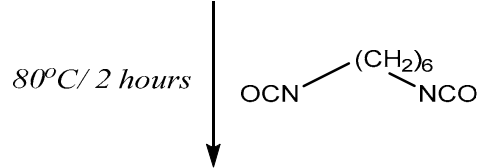

\section{PU-DOD/PCLDO}

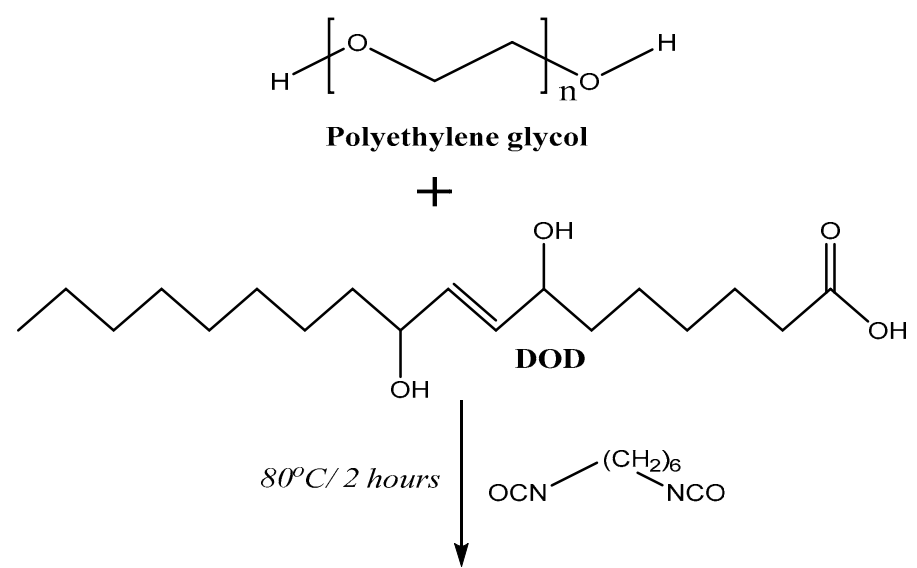

PU-DOD/PEG

Figure 7. Reaction schemes for the synthesis of PU-DOD/ polycaprolactone diol (PCLDO) and PU-DOD/ polyethylene glycol (PEG).
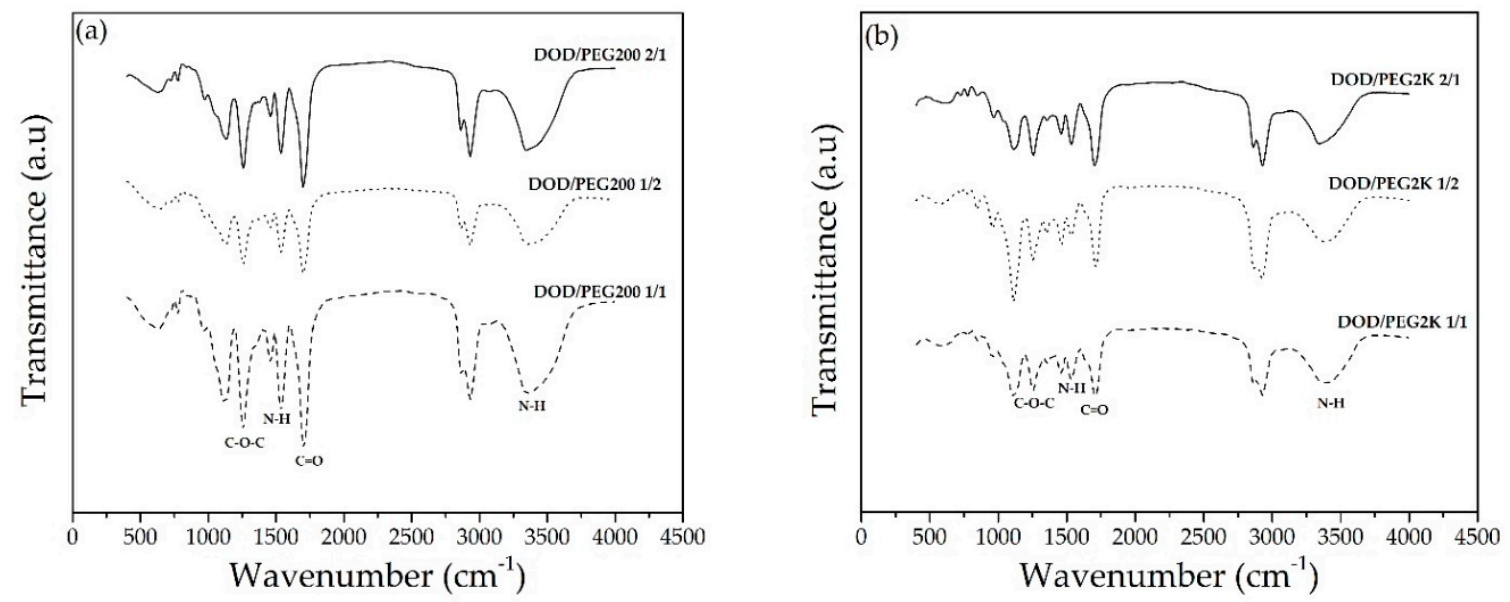

Figure 8. Cont. 


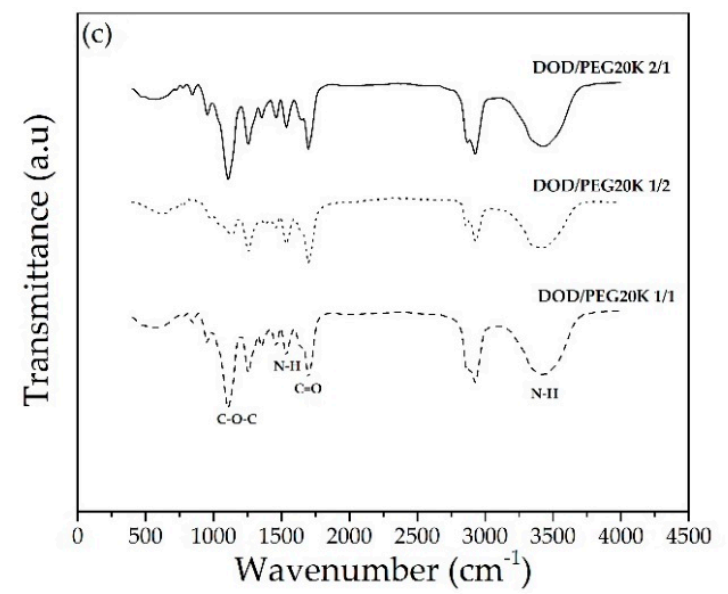

Figure 8. FTIR spectra of (a) PU-DOD/PEG200, and (d) PU-DOD/PCLDO.

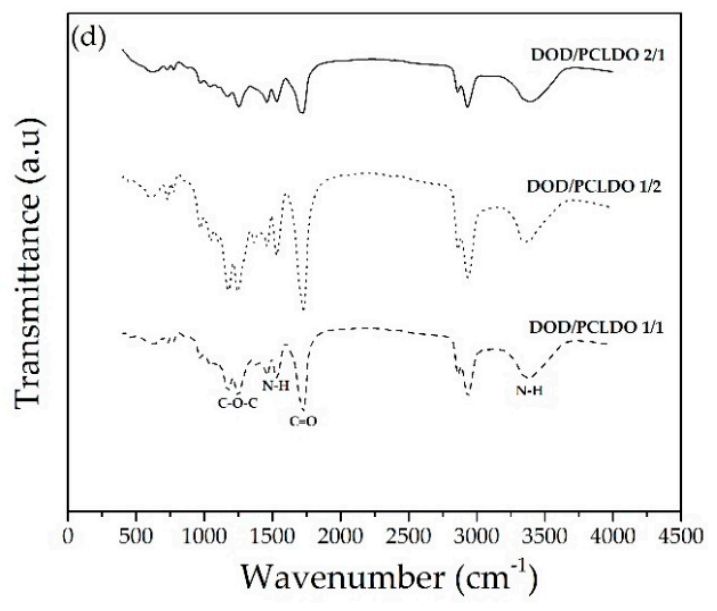

(b) PU-DOD/PEG2K, (c) PU-DOD/PEG20K,

The TGA curves of all polymeric samples displayed a slow degradation at the beginning and then a rapid decomposition process (Figure 9). Their degradation included three steps similar to PU-DOD: the first step from $230^{\circ} \mathrm{C}$ to $350{ }^{\circ} \mathrm{C}$ due to the decomposition of unstable urethane bonds, followed by the second step from $350{ }^{\circ} \mathrm{C}$ to $470{ }^{\circ} \mathrm{C}$ related with the degradation of the polyol segments, and finally the last step higher than $470{ }^{\circ} \mathrm{C}$ where the sample was completely decomposed.

Figure 9 compares various PUs possessing three hard segment contents based on the weight loss with temperature. It is evident that the first degradation step varies within $5-15{ }^{\circ} \mathrm{C}$ for PU-DOD/PCLDO and PU-DOD/PEG, indicating the role of the hard segment structure during the first step of degradation. In this context, other chain extenders such as 1,3-propanediol and 1,4-butanediol also show promising results and are potential candidates for bio-based PUs [31]. The $T_{10 \%}$ of PU-DOD/PEG and PU-DOD/PCLDO increased with increasing the fraction of PEG or PCLDO in the polymer. Among these polymers, PU-DOD/PEG20K had the highest $T_{10 \%}\left(290{ }^{\circ} \mathrm{C}\right)$ and PU-DOD/PCLDO had the lowest $T_{10 \%}\left(273^{\circ} \mathrm{C}\right)$. Thus, it can be concluded that PU-DOD/PEG20K possesses higher thermal stability than the others [33].

At a temperature higher than $160{ }^{\circ} \mathrm{C}$, urethane bonds reach a simultaneous reversible state of dissociation and re-association, as reported previously [32]. Depending on the polymer type, this phenomenon turns irreversible at about $200{ }^{\circ} \mathrm{C}$. Therefore, it can be assumed that during the first-stage urethane bond, degradation occurs and the urethane function with HMDI is less stable. Meanwhile, the second degradation step at a similar temperature shows the degradation of polyol, the soft polyurethane segment. A similar observation was previously made for vegetable oil-based PU [9,32]. Lastly, the third stage of degradation occurs at a similar temperature range of $415-465{ }^{\circ} \mathrm{C}$, depending on the PU type. This could be related to the disintegration of fragments produced in the previous stage.

Figure 10 shows the stress-strain curves of PU films based on various combinations of DOD and PEG/PCLDO. When DOD was combined with PEG, the polymer displayed quite elastic regions in the beginning. In the curves of PU-DOD/PCLDO, elastic regions are initially observed, followed by yield points and plastic behavior. The increasing content of PCLDO within the polymer exhibited a longer plastic region. 

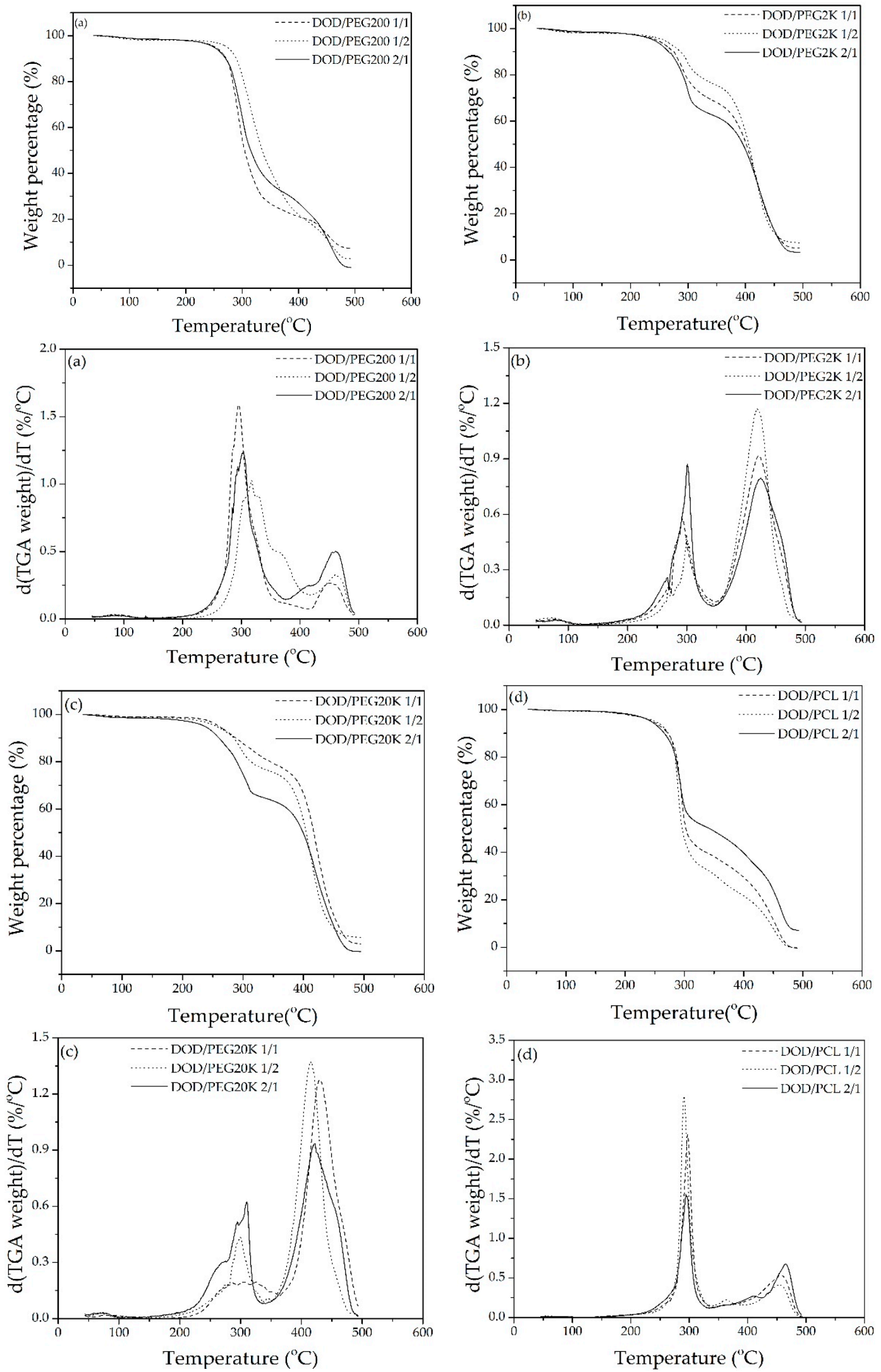

Figure 9. TGA curves and their derivative curves of (a) PU-DOD/PEG200, (b) PU-DOD/PEG2K, (c) PU-DOD/PEG20K, and (d) PU-DOD/PCLDO. 

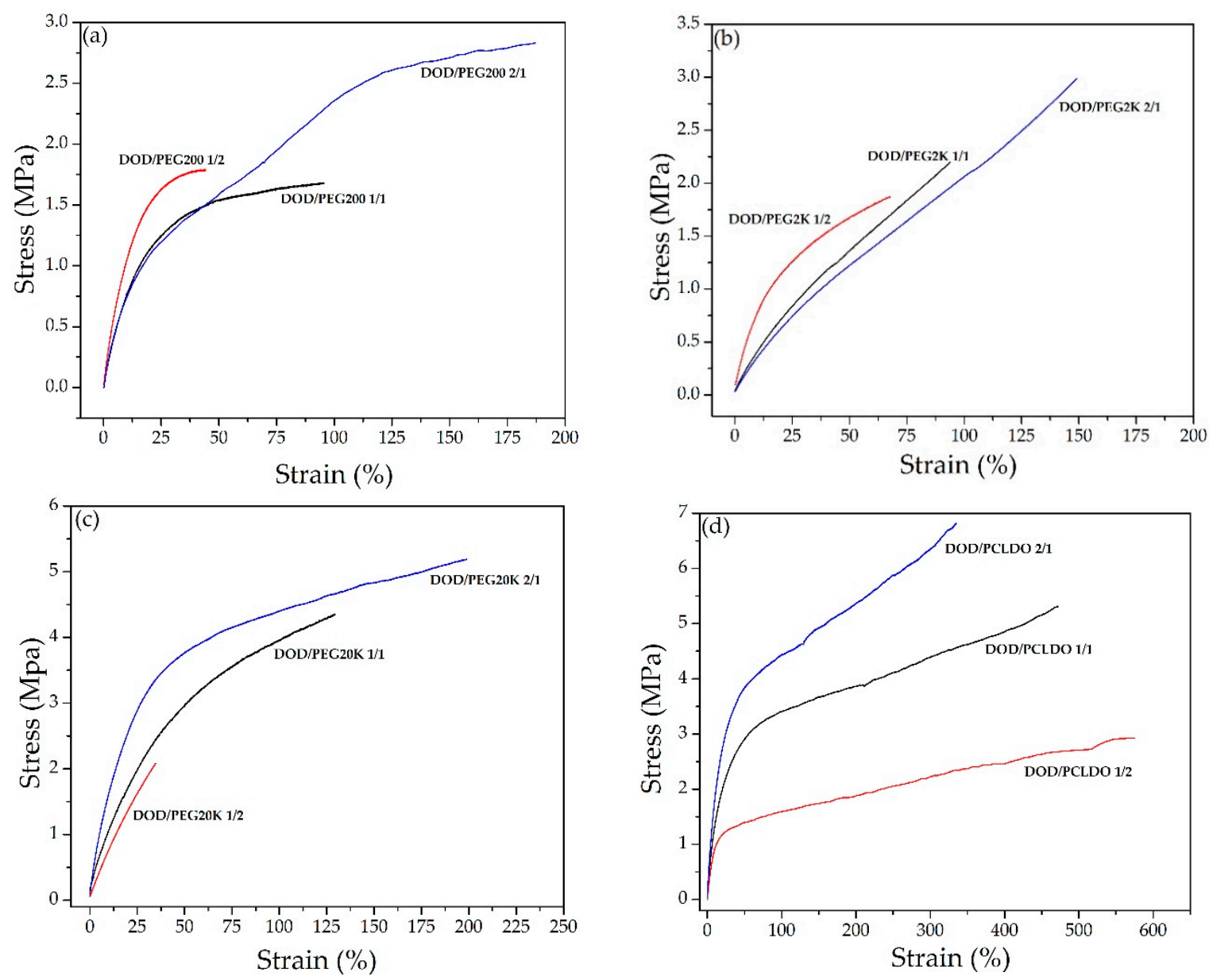

Figure 10. Stress-strain curves of (a) PU-DOD/PEG200, (b) PU-DOD/PEG2K, (c) PU-DOD/PEG20K, and (d) PU-DOD/PCLDO.

The tensile strength and elongation at break of all PU-DOD/PEG and PU-DOD/PCLDO samples were also evaluated compared to PU-DOD at the same NCO/OH ratio of 1.4 (Table 2). The tensile strength of PU-DOD/PCLDO was lower while the elongation at break was higher compared to PU-DOD (Figure 10). PCLDO decreased the tensile strength by increasing the soft segment of PU when mixed with DOD. As the fraction of PCLDO increased, the elongation at break of PU-DOD/PCLDO increased from $335 \%$ to $576 \%$ and the tensile strength decreased from $6.83 \mathrm{MPa}$ to $2.92 \mathrm{MPa}$. The elongation at break of PU-DOD/PEG ranged from $34 \%$ to $200 \%$ and the tensile strength increased with increasing molecular weight of PEG. The highest tensile strength of PU-DOD/PEG200 was $2.83 \mathrm{MPa}$ and reached 5.18 MPa for PU-DOD/PEG20K. Mechanical properties data show that the hardness decreases as the content of other polyols increases during the synthesis of PUs from DOD and other polyols. In all cases, a polyol mixture of 2:1 displayed the highest tensile strength and elongation at break, except when PCLDO was used with DOD. PU-DOD/PCLDO showed the characteristics of elastomers with high elongation (over 335\%) and low tensile strength (below $7 \mathrm{MPa}$ ), while PU-DOD/PEG showed plastic properties with a lower elongation at break (below 200\%). The TGA results show that PU-DOD/PEG20K had higher thermal stability than the other polymers. 
Table 2. Thermal and mechanical properties of PUs from DOD with PEG or PCLDO.

\begin{tabular}{|c|c|c|c|c|c|}
\hline \multirow{2}{*}{$\begin{array}{l}\text { Weight Ratio of DOD } \\
\text { to PEG or PCLDO }\end{array}$} & \multicolumn{3}{|c|}{ TGA in Nitrogen $\left({ }^{\circ} \mathrm{C}\right)$} & \multirow{2}{*}{$\begin{array}{l}\text { Elongation at } \\
\text { Break (\%) }\end{array}$} & \multirow{2}{*}{$\begin{array}{c}\text { Tensile } \\
\text { Strength (MPa) }\end{array}$} \\
\hline & $T_{10 \%}$ & $T_{50 \%}$ & $T_{\max }($ first/second $)$ & & \\
\hline \multicolumn{6}{|c|}{ PU-DOD/PEG200 } \\
\hline $2 / 1$ & 266 & 313 & $303 / 461$ & $187 \pm 5.22$ & $2.83 \pm 0.19$ \\
\hline $1 / 1$ & 272 & 304 & $296 / 449$ & $95.4 \pm 9.74$ & $1.68 \pm 0.12$ \\
\hline $1 / 2$ & 285 & 336 & $318 / 460$ & $45.5 \pm 3.59$ & $1.79 \pm 0.23$ \\
\hline \multicolumn{6}{|c|}{ PU-DOD/PEG2K } \\
\hline $2 / 1$ & 270 & 395 & $301 / 425$ & $149 \pm 5.06$ & $2.99 \pm 0.15$ \\
\hline $1 / 1$ & 276 & 401 & $293 / 421$ & $94.0 \pm 5.07$ & $2.21 \pm 0.28$ \\
\hline $1 / 2$ & 287 & 405 & $299 / 419$ & $68.9 \pm 5.92$ & $1.89 \pm 0.38$ \\
\hline \multicolumn{6}{|c|}{ PU-DOD/PEG20K } \\
\hline $2 / 1$ & 273 & 401 & $310 / 422$ & $200 \pm 1.80$ & $5.18 \pm 0.82$ \\
\hline $1 / 1$ & 285 & 417 & $299 / 425$ & $129 \pm 3.82$ & $4.38 \pm 0.33$ \\
\hline $1 / 2$ & 290 & 409 & $300 / 415$ & $34.7 \pm 0.68$ & $2.11 \pm 0.18$ \\
\hline \multicolumn{6}{|c|}{ PU-DOD/PCLDO } \\
\hline $2 / 1$ & 266 & 342 & $295 / 465$ & $335 \pm 5.22$ & $6.83 \pm 0.24$ \\
\hline $1 / 1$ & 272 & 302 & $297 / 457$ & $472 \pm 10.30$ & $5.32 \pm 0.68$ \\
\hline $1 / 2$ & 273 & 296 & $291 / 453$ & $576 \pm 13.30$ & $2.92 \pm 0.41$ \\
\hline
\end{tabular}

\section{Conclusions}

A bio-based polyol, DOD, was produced by P. aeruginosa PR3 using olive oil as a substrate. PUs prepared from DOD with an $\mathrm{NCO} / \mathrm{OH}$ ratio of 1.4 were found to be amorphous polymers with an elongation at break and tensile strength of $59.3 \%$ and $37.9 \mathrm{MPa}$, respectively. Mixing DOD with PCLDO or PEG at different weight ratios further enhanced the diversity of PU-DOD. This study demonstrates that natural oils can be effectively bio-converted to HFAs, which can act as building blocks to synthesize bio-based PUs.

Author Contributions: B.S.K. conceptualized the whole work. T.K.T. and P.K. designed and carried out the experiments. T.K.T., P.K., and B.S.K. wrote this paper. H.-R.K. and C.T.H. provided strain and analytical methods. All authors reviewed and approved the manuscript.

Funding: This research was supported by the National Research Foundation of Korea (NRF-2017R1A2B4002371). Acknowledgments: T.K.T. and P.K. are thankful for the financial support provided by a Brain Korea 21 plus project.

Conflicts of Interest: The authors declare no conflict of interest.

\section{References}

1. Akindoyo, J.O.; Beg, M.D.H.; Ghazali, S.; Islam, M.R.; Jeyaratnam, N.; Yuvaraj, A.R. Polyurethane types, synthesis and applications-A review. RSC Adv. 2016, 6, 114453-114482. [CrossRef]

2. Ding, H.; Xia, C.; Wang, J.; Wang, C.; Chu, F. Inherently flame-retardant flexible bio-based polyurethane sealant with phosphorus and nitrogen-containing polyurethane prepolymer. J. Mater. Sci. 2016, 51, 5008-5018. [CrossRef]

3. Hu, S.; Wan, C.; Li, Y. Production and characterization of biopolyols and polyurethane foams from crude glycerol based liquefaction of soybean straw. Bioresour. Technol. 2012, 103, 227-233. [CrossRef] [PubMed]

4. Tan, S.; Abraham, T.; Ference, D.; Macosko, C.W. Rigid polyurethane foams from a soybean oil-based Polyol. Polymer 2011, 52, 2840-2846. [CrossRef]

5. Wu, C.; Huang, X.; Wang, G.; Wu, X.; Yang, K.; Li, S.; Jiang, P. Hyperbranched-polymer functionalization of graphene sheets for enhanced mechanical and dielectric properties of polyurethane composites. J. Mater. Chem. 2012, 22, 7010-7019. [CrossRef]

6. Li, Z.; Zhang, R.; Moon, K.S.; Liu, Y.; Hansen, K.; Le, T.; Wong, C.P. Highly conductive, flexible, polyurethane-based adhesives for flexible and printed electronics. Adv. Funct. Mater. 2013, 23, 1459-1465. [CrossRef] 
7. Pfister, D.P.; Xia, Y.; Larock, R.C. Recent advances in vegetable oil-based polyurethanes. Chem. Sus. Chem. 2011, 4, 703-717. [CrossRef] [PubMed]

8. Miao, S.; Zhang, S.; Su, Z.; Wang, P. A novel vegetable oil-lactate hybrid monomer for synthesis of high-Tg polyurethanes. J. Polym. Sci. Pol. Chem. 2010, 48, 243-250. [CrossRef]

9. Hojabri, L.; Kong, X.; Narine, S.S. Fatty acid-derived diisocyanate and bio-based polyurethane produced from vegetable oil: Synthesis, polymerization, and characterization. Biomacromolecules 2009, 10, 884-891. [CrossRef] [PubMed]

10. Miao, S.; Zhang, S.; Su, Z.; Wang, P. Synthesis of bio-based polyurethanes from epoxidized soybean oil and isopropanolamine. J. Appl. Polym. Sci. 2013, 127, 1929-1936. [CrossRef]

11. Feng, Y.; Liang, H.; Yang, Z.; Yuan, T.; Luo, Y.; Li, P.; Yang, Z.; Zhang, C. A solvent-free and scalable method to prepare soybean-oil-based polyols by thiol-ene photo-click reaction and bio-based polyurethanes therefrom. ACS Sustain. Chem. Eng. 2017, 5, 7365-7373. [CrossRef]

12. Zhang, C.; Ding, R.; Kessler, M.R. Reduction of epoxidized vegetable oils: A novel method to prepare bio-based polyols for polyurethanes. Macromol. Rapid Commun. 2014, 35, 1068-1074. [CrossRef] [PubMed]

13. Zhang, C.; Li, Y.; Chen, R.; Kessler, M.R. Polyurethanes from solvent-free vegetable oil-based polyols. ACS Sustain. Chem. Eng. 2014, 2, 2465-2476. [CrossRef]

14. Lligadas, G.; Ronda, J.C.; Galià, M.; Cádiz, V. Renewable polymeric materials from vegetable oils: A perspective. Mater. Today 2013, 16, 337-343. [CrossRef]

15. Hou, C.T.; Brown, W.; Labeda, D.P.; Abbott, T.P.; Weisleder, D. Microbial production of a novel trihydroxy unsaturated fatty acid from linoleic acid. J. Ind. Microbiol. Biotechnol. 1997, 19, 34-38. [CrossRef] [PubMed]

16. Kim, H.; Gardner, H.W.; Hou, C.T. 10(S)-Hydroxy-8(E)-octadecenoic acid, an intermediate in the conversion of oleic acid to 7,10-dihydroxy-8(E)-octadecenoic acid. J. Am. Oil Chem. Soc. 2000, 77, 95-99. [CrossRef]

17. Kim, H.; Gardner, H.W.; Hou, C.T. Production of isomeric 9,10,13 (9,12,13)-trihydroxy-11E (10E)-octadecenoic acid from linoleic acid by Pseudomonas aeruginosa PR3. J. Ind. Microbiol. Biotechnol. 2000, 25, 109-115. [CrossRef]

18. Kuo, T.M.; Manthey, L.K.; Hou, C.T. Fatty acid bioconversions by Pseudomonas aeruginosa PR3. J. Am. Oil Chem. Soc. 1998, 75, 875-879. [CrossRef]

19. Bae, J.-H.; Suh, M.-J.; Lee, N.-Y.; Hou, C.T.; Kim, H.-R. Production of a value-added hydroxy fatty acid, 7,10-dihydroxy-8(E)-octadecenoic acid, from high oleic safflower oil by Pseudomonas aeruginosa PR3. Biotechnol. Bioprocess Eng. 2010, 15, 953-958. [CrossRef]

20. Chang, I.-A.; Kim, I.-H.; Kang, S.-C.; Hou, C.T.; Kim, H.-R. Production of 7, 10-dihydroxy-8(E)-octadecenoic acid from triolein via lipase induction by Pseudomonas aeruginosa PR3. Appl. Microbiol. Biotechnol. 2007, 74, 301-306. [CrossRef] [PubMed]

21. Kuo, T.M.; Ray, K.J.; Manthey, L.K. A facile reactor process for producing 7,10-dihydroxy-8(E)-octadecenoic acid from oleic acid conversion by Pseudomonas aeruginosa. Biotechnol. Lett. 2003, 25, 29-33. [CrossRef] [PubMed]

22. Hou, C.T.; Bagby, M.O. Production of a new compound, 7,10-dihydroxy-8-(E)-octadecenoic acid from oleic acid by Pseudomonas sp. PR3. J. Ind. Microbiol. 1991, 7, 123-129. [CrossRef]

23. Suh, M.-J.; Baek, K.-Y.; Kim, B.-S.; Hou, C.T.; Kim, H.-R. Production of 7,10-dihydroxy-8(E)-octadecenoic acid from olive oil by Pseudomonas aeruginosa PR3. Appl. Microbiol. Biotechnol. 2011, 89, 1721-1727. [CrossRef] [PubMed]

24. Sohn, H.-R.; Hou, C.T.; Soo Kim, B.; Kim, H.-R. Evaluation of environmental parameters for production of 7, 10-dihydroxy-8(E)-octadecenoic acid from olive oil by Pseudomonas aeruginosa PR3. Biocatal. Agric. Biotechnol. 2013, 2, 352-356. [CrossRef]

25. Kumar, P.; Jun, H.-B.; Kim, B.S. Co-production of polyhydroxyalkanoates and carotenoids through bioconversion of glycerol by Paracoccus sp. strain LL1. Int. J. Biol. Macromol. 2018, 107, 2552-2558. [CrossRef] [PubMed]

26. Kim, H.-M.; Kim, H.-R.; Hou, C.T.; Kim, B.S. Biodegradable photo-crosslinked thin polymer networks based on vegetable oil hydroxy fatty acids. J. Am. Oil Chem. Soc. 2010, 87, 1451-1459. [CrossRef]

27. Kim, H.-M.; Kim, H.-R.; Kim, B.S. Soybean oil-based photo-crosslinked polymer networks. J. Polym. Environ. 2010, 18, 291-297. [CrossRef] 
28. Ellamar, J.B.; Dasangrandhi, C.; Kim, Y.S.; Kim, I.H.; Kim, H.R. Microbial bioconversion of natural Philippine nut oils into a value-added hydroxy fatty acid, 7, 10-dihydroxy-8(E)-octadecenoic acid. Korean J. Food Sci. Technol. 2017, 49, 28-34.

29. Leventis, N.; Chidambareswarapattar, C.; Mohite, D.P.; Larimore, Z.J.; Lu, H.; Sotiriou-Leventis, C. Multifunctional porous aramids (aerogels) by efficient reaction of carboxylic acids and isocyanates. J. Mater. Chem. 2011, 21, 11981-11986. [CrossRef]

30. Semsarzadeh, M.A.; Navarchian, A.H. Effects of NCO/OH ratio and catalyst concentration on structure, thermal stability, and crosslink density of poly(urethane-isocyanurate). J. Appl. Polym. Sci. 2003, 90, 963-972. [CrossRef]

31. Corcuera, M.A.; Rueda, L.; Fernandez d'Arlas, B.; Arbelaiz, A.; Marieta, C.; Mondragon, I.; Eceiza, A. Microstructure and properties of polyurethanes derived from castor oil. Polym. Degrad. Stab. 2010, 95, 2175-2184. [CrossRef]

32. Hablot, E.; Zheng, D.; Bouquey, M.; Avérous, L. Polyurethanes based on castor oil: Kinetics, chemical, mechanical and thermal properties. Macromol. Mater. Eng. 2008, 293, 922-929. [CrossRef]

33. Wang, T.-L.; Hsieh, T.-H. Effect of polyol structure and molecular weight on the thermal stability of segmented poly(urethaneureas). Polym. Degrad. Stab. 1997, 55, 95-102. [CrossRef]

(C) 2018 by the authors. Licensee MDPI, Basel, Switzerland. This article is an open access article distributed under the terms and conditions of the Creative Commons Attribution (CC BY) license (http://creativecommons.org/licenses/by/4.0/). 